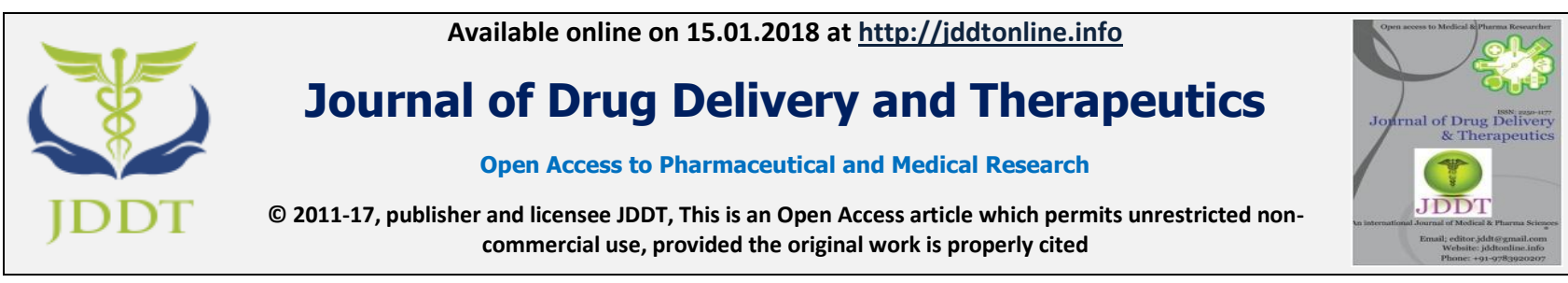

Open $\odot$ Access

Re search Article

\title{
A PROSPECTIVE OBSERVATIONAL STUDY ON EFFECTS OF HEPATOPROTECTIVE AGENTS IN ALCOHOLIC LIVER DISEASE AT A TERTIARY CARE HOSPITAL
}

\author{
Hanan Fatima Ahmed ${ }^{1}$, Sabiha Naseem ${ }^{1}$, Habeeb Unnisa ${ }^{1}$, Asfia Amreen ${ }^{1}$, Javed Akhtar Ansari ${ }^{1 *}$, \\ Rafia Sultana ${ }^{2}$
}

${ }^{1}$ Department of Pharmacy Practice (PharmD), MESCO College of Pharmacy, Osmania University, Hyderabad, T.S. India

${ }^{2}$ Department of Clinical Pharmacology, Osmania General Hospital, Hyderabad, T.S. India

\begin{abstract}
Drug utilization evaluation of hepatoprotective drugs is important in view of the spectrum of effect and associated risks with their therapy. The study was designed to evaluate the effects and adverse effects of hepatoprotective agents. A prospective, observational study was carried out for a period of 6 months at Osmania General Hospital (a tertiary care hospital). 120 patients were evaluated receiving corticosteroids, pentoxifylline, ursodeoxycholic acid for observing a trend in hepatic parameters and its outcomes. Ursodeoxycholic acid (81.66\%) was the most commonly prescribed drug in almost all cases of alcoholic liver diseases followed by pentoxifylline $(10 \%)$ in hepatorenal syndrome and then prednisolone $(8.33 \%)$ in fatty liver. 67 cases were reported to have the significant drop in liver transaminases and bilirubin levels. Ursodeoxycholic acid resulted in a drop of $25 \%$ serum bilirubin and $35 \%$ drop in serum ALT (alanine transaminase) and 33\% drop in serum AST (aspartate transaminase) in patients in a time gap of 1 week. Among 120 cases 94 were males (78.05\%) and 26 females (21.04\%) and maximum patients with alcoholic liver disease belonged to age group of 30-40 years (27.6\%). Ursodeoxycholic acid (300 mg once daily) is used as an off-label drug for all types of alcoholic liver disease and also for viral hepatitis. Though Ursodeoxycholic acid showed a significant drop in liver transaminases and serum bilirubin levels in cirrhotic patients a better alternative lie in liver transplantation as long as they remain abstinent from alcohol.
\end{abstract}

Keywords: Alcoholic liver diseases, Hepatoprotective agents, Liver transaminases, Bilirubin, Paired $t$-test.

Article Info: Received 04 Nov, 2017; Review Completed 08 Dec, 2017; Accepted 12 Dec, 2017; Available online 15 Jan, 2018

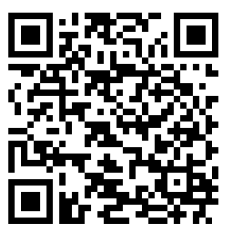

\section{Cite this article as:}

Ahmed HF, Naseem S, Unnisa H, Amreen A, Ansari JA, Sultana R, A prospective observational study on effects of hepatoprotective agents in alcoholic liver disease at a tertiary care hospital, Journal of Drug Delivery and Therapeutics. 2018; 8(1):7-12

DOI: http://dx.doi.org/10.22270/jddt.v8i1.1544

*Address for Correspondence

Javed Akhtar Ansari, Department of Pharmacy Practice (PharmD), MESCO College of Pharmacy, Osmania University, Hyderabad, T.S. India. E-mail: javed.ansari47@gmail.com

\section{INTRODUCTION}

Drug utilization evaluation of hepatoprotective drugs is important in view of the spectrum of effect and associated risks with their therapy. The study was designed to evaluate the effects and adverse effects of hepatoprotective agents. Drug use indicators are intended to determine definite aspects of health providers \& drug use in a hospital or health center. Indicators will give data to health care managers regarding drug use, prescribing habits \& important views of patient care. ${ }^{1}$ The drugs capable of preventing alcohol-related injury or limiting and repairing damage already sustained might play an important role in the management of alcoholic patients. A number of socalled hepatoprotective agents are available and are extensively used, however the evidence that their use without abstinence conferring any benefits is poor ${ }^{2}$.

The standard therapy for treating alcoholic hepatitis is corticosteroids. ${ }^{3}$ Corticosteroids act by reducing inflammatory cytokines such as tumor necrosis factor- $\alpha$ (TNF- $\alpha$ ), intercellular adhesion molecule 1, interleukin (IL)-6 and IL-8. ${ }^{4} 5$ Inflammation is a major component 
of $\mathrm{AH}$ pathogenesis. Prednisolone is given orally in a dose of $40-60 \mathrm{mg} / \mathrm{d}$ for a total duration of 4 weeks. The treatment is then tapered over next 2-3 week. Being the first line agent in alcoholic hepatitis prednisolone was not prescribed due to increased susceptibility to infections as these patients are prone to variceal bleeding. ${ }^{6}$

For patients who have contraindications to steroids, the second option for treatment is oral pentoxifylline (PTX), a phosphodiesterase and a possible TNF- $\alpha$ inhibitor. Pentoxifylline is given orally at a dose of $400 \mathrm{mg}$ three times a day for a total duration of 28 days. The exact mechanism of action of pentoxifylline is not entirely clear. Neutralization of TNF- $\alpha$ by pentoxifylline may explain the protective effect of this drug on HRS (hepatorenal syndrome). ${ }^{7}$

Ursodeoxycholic acid (UDCA) is a physiologic hydrophilic dihydroxy bile acid which was approved by FDA for cholesterol gallstone dissolution and primary biliary cirrhosis. ${ }^{8-11}$ UDCA does not affect long-term survival or transplant-free survival but achieves a $25 \%$ drop in serum bilirubin a $35 \%$ drop in serum alanine transaminase, $33 \%$ in aspartate transaminase. ${ }^{12-15}$ Hence, it is used as an off-label treatment for treating alcoholic liver disease. The study was carried out to evaluate utilization of hepatoprotective agents in subjects affected with the alcoholic liver disease.

\section{MATERIALS AND METHODS}

Study design, site and ethical approval

The present prospective, observational study was carried out at Osmania General Hospital, a tertiary care teaching hospital in Hyderabad, India for a period of 6 months (January 2016 to June 2016). Before initiating the study, the study was approved by Institutional Ethics Committee (IEC) bearing No. MCP/IEC/PD/PR/09.

\section{Study criteria}

The subjects included were patients of either sex above 18 years of age undergoing treatment in general medicine department in the hospital who were diagnosed with the alcoholic liver disease. The patients under 18 years age group, pregnant and lactating women, patients with drug-induced liver disease and liver carcinoma and with comorbid cardiac diseases were excluded from our study to have a better outcome of the study.

\section{Data collection}

Patients who corroborate the study protocol criteria were included and the required data were collected from the patient case sheet. The patient's physiological parameters were monitored timely and were recorded in a pre-designed form which included data like ALT, AST, and serum bilirubin. Changes in AST, ALT, and serum bilirubin were considered in patients being treated with ursodeoxycholic acid. A graph was plotted with AST, ALT and serum bilirubin at the time of admission and then after being treated with ursodeoxycholic acid.

The CAGE (Concern/Cut-down, Anger, Guilt, and Eyeopener) questionnaire has been used in identifying alcoholic problems. ${ }^{16}$

During the present study medication chart of patient was also observed for any drug-drug interaction relating the hepatoprotective drug used and any adverse drug reactions felt by the patients on hepatoprotective treatment.

\section{Statistical analysis}

Data analysis was done by using the software Prism 0.5 . Differences between means of groups were compared using student $t$-test (paired $t$-test). The results were expressed in terms of number and percentage.

\section{RESULTS}

\section{Demographic details of subjects}

A total of 120 subjects were assessed for the 6 months study period. The demographic details of study participants are depicted in figure 1 . The result shows that the incidence of fatty liver was highest in the age group of $30-40(5.83 \%)$ and alcoholic hepatitis $(3.63 \%)$ in the age group of $40-50$ and cirrhosis $(18.33 \%)$ in the age group of $40-50$ and viral hepatitis $(5.83 \%)$ in the age group of 20-30.

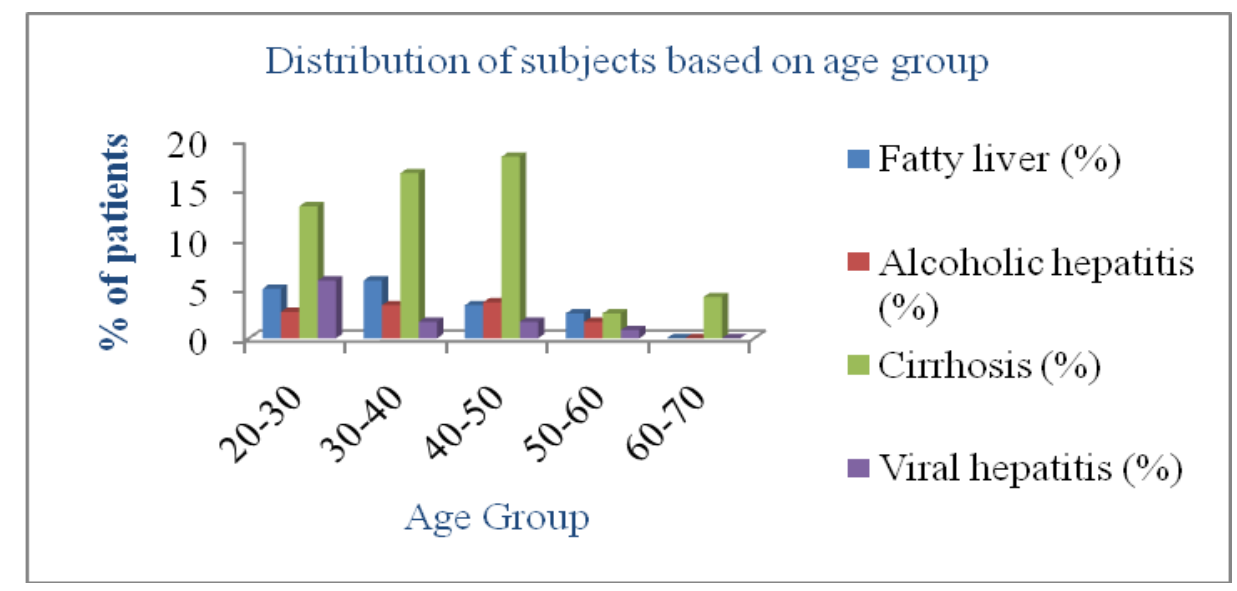

Figure 1: Distribution of subjects based on age group. 
Distribution of disease based on gender

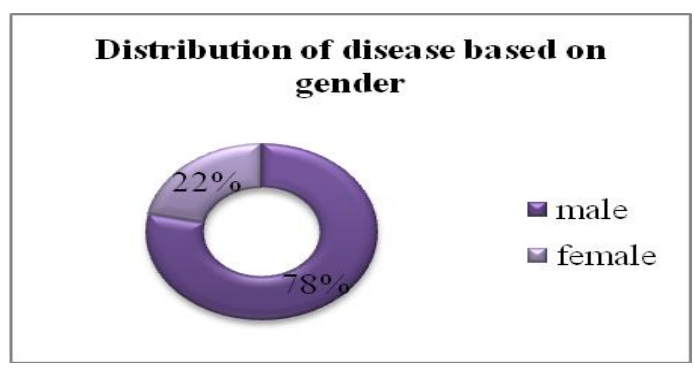

Figure 2: Distribution of subjects based upon age groups.
The total number of male patients was more than female in our study i.e. $78.33 \%$ and $21.66 \%$ respectively (figure 2).

Duration of intake of alcohol and its effect on gender

The result shows that women are more prone to develop alcoholic liver and are more likely to progress to liver fibrosis earlier than men even at smaller amounts of consumption. The mean duration of intake of alcohol among women was observed within 1-5 years and in the case of men, it was observed to be within 10-15 years. The data is shown in figure 3 .

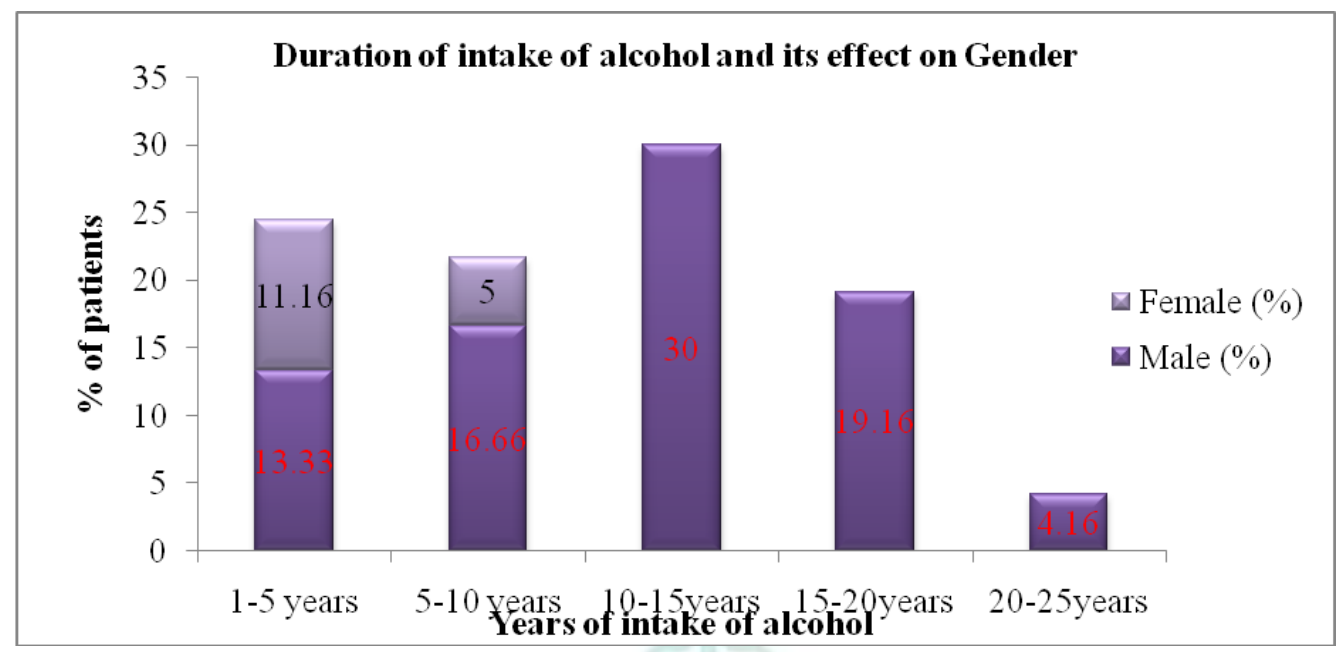

Figure 3: Duration of intake of alcohol and its effect on gender

Differentiating causes of liver damage based on AST/ALT ratio

The highest number of cases was of cirrhosis $(55.83 \%)$ depending on AST/ALT ratio followed by Alcoholic hepatitis $(33.33 \%)$ and viral hepatitis $(10.83 \%)$. This data is shown in table 1.

Table 1: Differentiating causes of liver damage based on AST/ALT ratio.

\begin{tabular}{|l|l|l|}
\hline Disease condition & AST/ALT ratio & \% of cases \\
\hline viral hepatitis & $0-1$ & 10.83 \\
\hline Cirrhosis & $1-2$ & 55.83 \\
\hline alcoholic hepatitis & $>2$ & 33.33 \\
\hline
\end{tabular}

\section{Hepatoprotective drugs utilization}

In this study ursodeoxycholic acid (81.66\%) was the most commonly prescribed drug in almost all cases of alcoholic liver diseases followed by pentoxifylline $(10 \%)$ in hepatorenal syndrome and then prednisolone $(8.33 \%)$ in fatty liver. The data is reported in figure 4 .

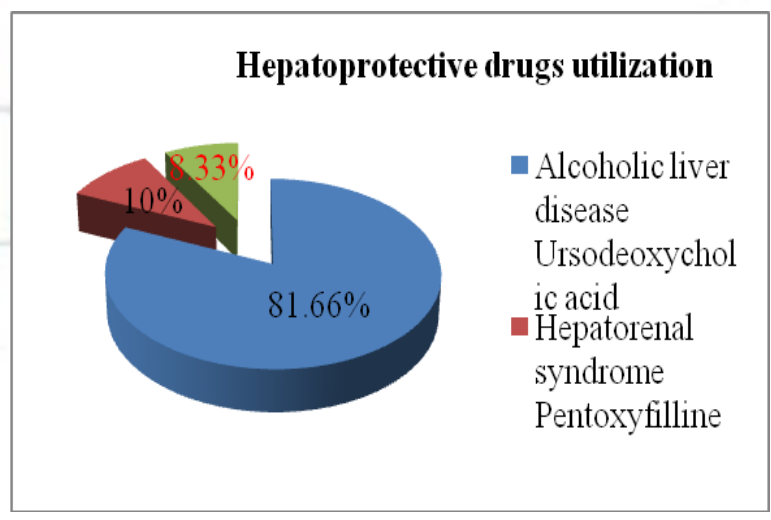

Figure 4: Hepatoprotective drugs utilization

Effect of ursodeoxycholic acid on Aspartate Transaminase, alanine transaminase, and serum bilirubin

The study showed drop of $25 \%$ serum bilirubin and $35 \%$ drop in serum alanine transaminase and 33\% drop in aspartate transaminase in patients receiving ursodeoxycholic acid in a time gap of 1 week. This is reported in figure 5, figure 6 and figure 7 for AST, ALT and serum bilirubin respectively. 


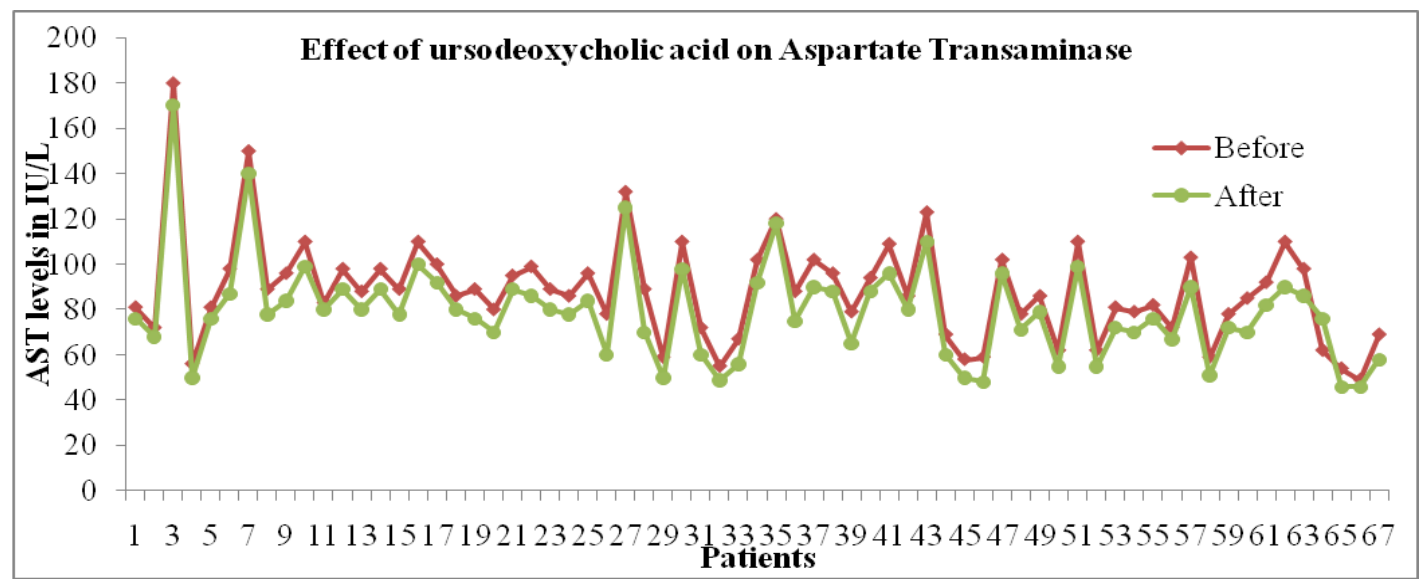

Figure 5: Effect of ursodeoxycholic acid on Aspartate Transaminase

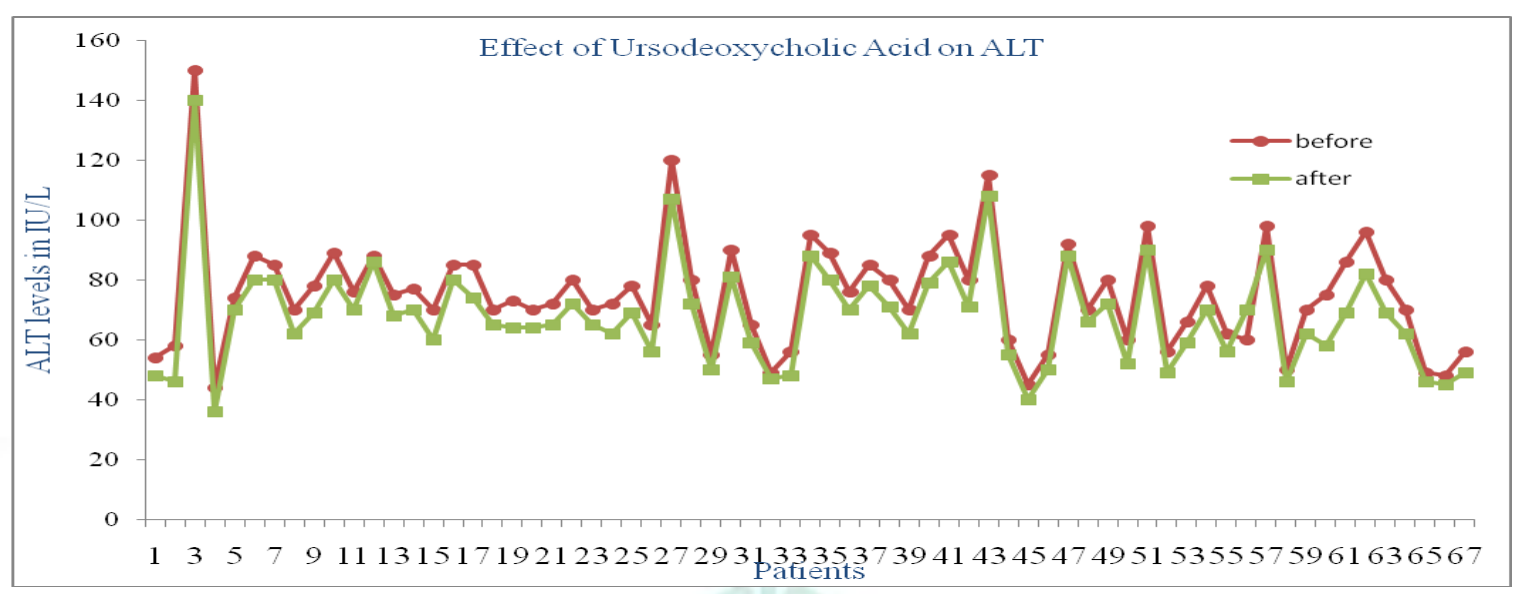

Figure 6: Effect of ursodeoxycholic acid on alanine transaminase

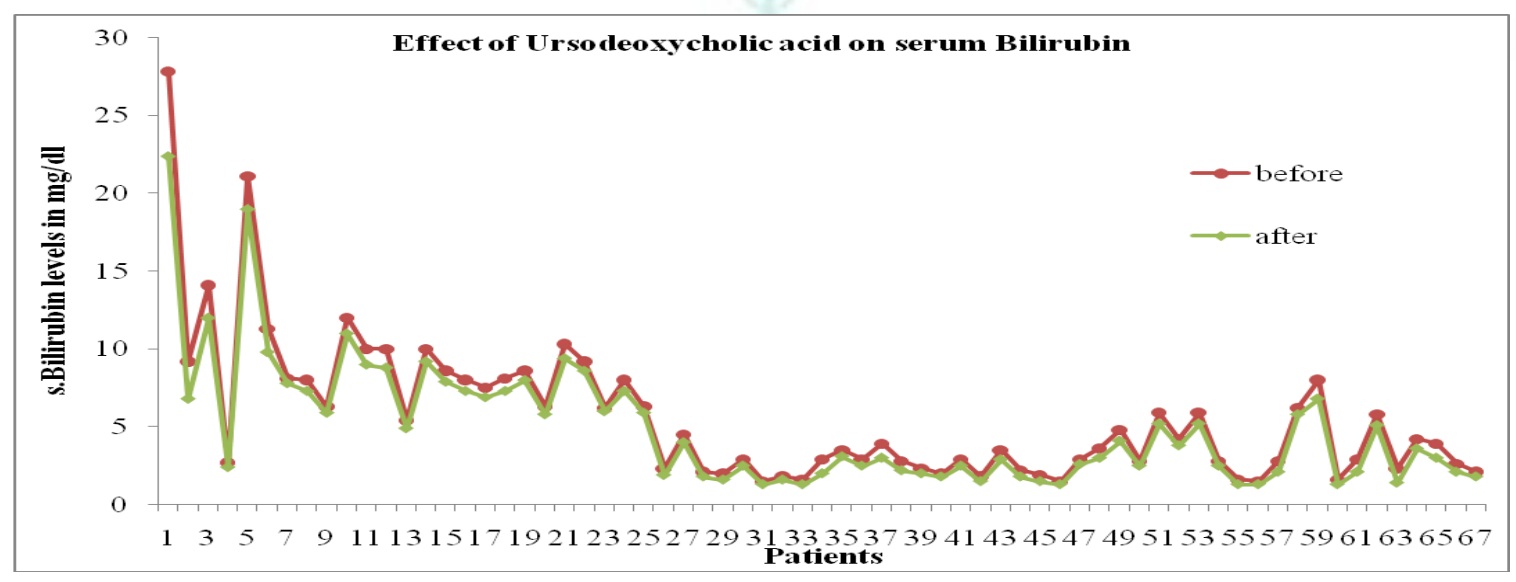

Figure 7: Effect of Ursodeoxycholic acid on serum Bilirubin

\section{Adverse effects}

A total of 120 cases of the alcoholic liver disease were recorded out of which 32 cases were identified with adverse effects. Ursodeoxycholic acid caused watery diarrhea in $20.83 \%$ of cases and pruritus in $4.16 \%$ of cases, pentoxifylline caused dizziness in $1.66 \%$ of cases. The data is recorded in table 2.
Table 2: Adverse effects

\begin{tabular}{|l|l|l|}
\hline \% of Cases & Adverse Effects & Drug Related \\
\hline $\mathbf{2 0 . 8 3}$ & Watery Diarrhea & Ursodeoxycholic Acid \\
\hline $\mathbf{1 . 6 6}$ & Dizziness & Pentoxifylline \\
\hline $\mathbf{4 . 1 6}$ & Pruritis & Ursodeoxycholic Acid \\
\hline
\end{tabular}


Statistical analysis

Table 3: Analysis of alanine transaminase values before and after administration of Ursodeoxycholic Aci

\begin{tabular}{|l|l|}
\hline Table Analyzed & Paired $\boldsymbol{t}$ test data \\
\hline Column B & After \\
\hline vs. & vs. \\
\hline Column A & Before \\
\hline Paired $\boldsymbol{t}$ test & $<0.0001$ \\
\hline P value pairing & Yes \\
\hline $\begin{array}{l}\text { Was the } \\
\text { significantly effective? }\end{array}$ & \\
\hline
\end{tabular}

Table 4: Analysis of aspartate transaminase values before and after administration of Ursodeoxycholic Acid

\begin{tabular}{|l|l|}
\hline Table Analyzed & Paired t test data \\
\hline Column B & After \\
\hline vs. & vs. \\
\hline Column A & Before \\
\hline Paired $\boldsymbol{t}$ test & $<0.0001$ \\
\hline P value & Yes \\
\hline $\begin{array}{l}\text { Was the pairing } \\
\text { significantly effective? }\end{array}$ & \\
\hline
\end{tabular}

Table 5: Analysis of bilirubin values before and after administration of Ursodeoxycholic Acid.

\begin{tabular}{|l|l|}
\hline Table Analyzed & Paired $\boldsymbol{t}$ test data \\
\hline Column B & After \\
\hline vs. & vs. \\
\hline Column A & Before \\
\hline Paired $\boldsymbol{t}$ test & $<0.0001$ \\
\hline P value pairing & Yes \\
\hline $\begin{array}{l}\text { Was the pas cective? } \\
\text { significantly effect }\end{array}$ & \\
\hline
\end{tabular}

\section{DISCUSSION}

In developing countries like India, the alcoholic liver disease remains the most common cause of morbidity and mortality. ${ }^{17}$ Alcoholic liver diseases occur in a majority of subjects who drink large quantities of ethanol on a daily basis for many years. The diagnostic criteria for alcoholic hepatitis are based entirely on the appropriate alcohol intake history, fever, jaundice, ascites, elevated WBC (white blood cells), AST $<400$ $\mathrm{IU} / \mathrm{mL}$ and elevated AST: ALT ratio. ${ }^{18}$ Liver biopsy may help confirm the diagnosis but is not required. Abstinence remains the cornerstone of management of all forms of the alcoholic liver disease. Prednisolone 40 $\mathrm{mg} /$ day for 28 days is the most widely opted treatment option; however it is contraindicated in patients with recent upper gastrointestinal bleeding, elevated creatinine or uncontrolled infection. Pentoxifylline 400 $\mathrm{mg}$ thrice daily for 28 days is an alternate treatment option. A potential benefit of pentoxifylline treatment is that it can be used in patients with infection and in patients with renal insufficiency. Consequently, liver transplantation remains an ultimate option for selected patients with liver failure due to chronic alcoholic liver damage.

A prospective, observational, noninvasive study was carried out at the department of General Medicine, Osmania General Hospital, a tertiary care teaching hospital, for a period of 6 months. During the study period, a total of 120 cases of the alcoholic liver disease were recorded from January 2016 to June 2016, out of which 67 cases were reported to have a significant drop in liver transaminases and bilirubin levels. Women are more prone to develop alcoholic liver and are more likely to progress to liver fibrosis earlier than men even at smaller amounts of consumption. Mean duration of intake of alcohol among women was observed within 15 years and in case of men it was observed to be within 10-15 years, which was similar to that of studies reported in literature by Bernadt et al. $1982,{ }^{19}$ Sato et al. 2001, ${ }^{20}$ Wechsler and Austin et al. 1998, ${ }^{21}$ and Barrio and Rodriguez et al. 2004. ${ }^{22}$ Gender specific susceptibility to alcohol hepatotoxicity has been attributed to women having lower gastric levels of alcohol dehydrogenase, leading to slower first-pass metabolism of alcohol, higher gut permeability, causing higher endotoxin levels after alcohol ingestion that in turn lead to more aggressive oxidative stress and inflammation, larger body fat content, resulting in a lower volume of distribution for alcohol.

The AST: ALT ratio was useful in differentiating the cause of liver damage, the AST: ALT ratio of 2 or more may be associated with alcoholic hepatitis and a ratio of $>1$ and $<2$ is suggestive of cirrhosis and less than 1 is associated with viral hepatitis. This is in accordance with the study of Vuittonet and Kenna et al. 2014. ${ }^{23}$ Many patients were contraindicated to corticosteroid therapy such as active infection and are more prone to variceal bleeding hence patients were switched to pentoxifylline which is in accordance with studies reported by Halegoua-De Marzio and Fenkel 2013. ${ }^{3}$ Ursodeoxycholic acid resulted in a drop of $25 \%$ serum bilirubin and $35 \%$ drop in serum alanine transaminase and $33 \%$ drop in aspartate transaminase in patients in a time gap of 1 week after administration of the drug which is in accordance with the study reported by Kotb $2012 .{ }^{24}$ Ursodeoxycholic acid toxicity included pruritis, severe watery diarrhea which is seen in the study of Kotb 2012. ${ }^{24}$ The drawback of glucocorticoid use in patients with alcoholic hepatitis is increased susceptibility to infections is according to the study by Thursz et al. (2015). ${ }^{25}$

\section{CONCLUSION}

The present study has demonstrated the effects of hepatoprotective agents on physiological parameters in alcoholic liver disease patients. The optimal management of alcoholic liver disease begins with therapeutic lifestyle changes, in which abstinence or dramatic reduction in alcohol use is crucial. Abstinence has a profound beneficial effect on survival at all stages of the disease. Corticosteroid being the first line agent in alcoholic liver disease was not prescribed due to increased susceptibility to infections and it also has a tendency to increase variceal bleeding. Pentoxifylline is 
considered to be a better alternative to glucocorticoid therapy particularly in patients who are at risk for hepatorenal syndrome (worsening creatinine, infection, hyponatremia). Ursodeoxycholic acid is used as an offlabel drug for all type of alcoholic liver diseases and also for viral hepatitis. Ursodeoxycholic acid resulted in a drop of $25 \%$ serum bilirubin and $35 \%$ drop in serum alanine transaminase and $33 \%$ drop in aspartate transaminase in patients in a time gap of 1 week. Management of alcoholic liver disease relies on abstaining from alcohol along with treating alcohol withdrawal, providing nutritional support and managing cirrhosis-related complications.

\section{REFERENCES}

1. Jackson MR, Danby CA, Alving BM. Heparinoid anticoagulation and topical fibrin sealant in heparin-induced thrombocytopenia. The Annals of Thoracic Surgery 1997; 64(6): 1815-7.

2. Morgan MY. Hepatoprotective agents in alcoholic liver disease. J Intern Med 1985; 218: 225-233.

3. Halegoua-De Marzio DL, Fenkel JM. Treatment of severe alcoholic hepatitis with corticosteroids and pentoxifylline. JAMA 2013; 310: 1029-30.

4. Spahr L, Rubbia-Brandt L, Pugin J, Giostra E, Frossard JL, Borisch B, Hadengue A. Rapid changes in alcoholic hepatitis histology under steroids: correlation with soluble intercellular adhesion molecule-1 in hepatic venous blood. J Hepatol 2001; 35: 582-589.

5. Taïeb J, Mathurin P, Elbim C, Cluzel P, Arce-Vicioso M, Bernard B, Opolon P, Gougerot-Pocidalo MA, Poynard T, Chollet-Martin S. Blood neutrophil functions and cytokine release in severe alcoholic hepatitis: effect of corticosteroids. $J$ Hepatol 2000; 32: 579-586.

6. Louvet A, Wartel F, Castel H, Dharancy S, Hollebecque A, Canva-Delcambre V. Infection in patients with severe alcoholic hepatitis treated with steroids: early response to therapy is the key factor. Gastroenterology. 2009; 137: 54148.

7. Akriviadis E, Botla R, Briggs W, Han S, Reynolds T, Shakil O. Pentoxifylline improves short-term survival in severe acute alcoholic hepatitis: a double-blind, placebo-controlled trial. Gastroenterology 2000; 119: 1637-1648.

8. Hagey LR, Crombie DL, Espinosa E, Carey MC, Igimi H, Hofmann AF. Ursodeoxycholic acid in the Ursidae: Biliary bile acids of bears, pandas, and related carnivores. J Lipid Res 1993; 34: 1911-7.

9. Bachrach WH, Hofmann AF. Ursodeoxycholic acid in the treatment of cholesterol cholelithiasis. part I. Dig Dis Sci 1982; 27: 737-761.

10. Roma MG, Toledo FD, Boaglio AC, Basiglio CL, Crocenzi FA, Sánchez Pozzi EJ. Ursodeoxycholic acid in cholestasis: Linking action mechanisms to therapeutic applications. Clin Sci (Lond.) 2011; 121: 523-44.

11. Leuschner U, Leuschner M, Sieratzki J, Kurtz W, Hübner K. Gallstone dissolution with ursodeoxycholic acid in patients with chronic active hepatitis and two years follow-up, A pilot study. Dig Dis Sci 1985; 30: 642-49.

12. Heathcote EJ, Cauch-Dudek K, Walker V, Bailey RJ, Blendis LM, Ghent $\mathrm{CN}$ et al. The Canadian multicentre double blind randomized controlled trial of ursodeoxycholic acid in primary biliary cirrhosis. Hepatology 1994; 19: 1149-56.
The pharmacist is the key person for better management of therapy based on stage and condition of the patient and to manage any unwanted effects. Sincere efforts has been taken to educate the patients on ill effects concerned with the usage of alcohol on health, family, social well-being and on community and to minimize any adverse effects (at least to some extent) by our dissertation.

Acknowledgement: The authors would like to acknowledge the patients and clinicians of Osmania General Hospital and the Principal and staff of MESCO College of pharmacy, Hyderabad, India.

Conflict of interest: None declared.

13. Degott C, Zafrani ES, Callard P, Balkau B, Poupon RE, Poupon R. Histopathological study of primary biliary cirrhosis and the effect of ursodeoxycholic acid treatment on histology progression. Hepatology 1999; 29: 1007-1012.

14. Gong Y, Huang ZB, Christensen E, Gluud C. Ursodeoxycholic acid for primary biliary cirrhosis. Cochrane Database Syst Rev 2008; 16: CD000551.

15. Reichen J. Review: ursodeoxycholic acid does not reduce risk for mortality or liver transplantation in primary biliary cirrhosis. ACP J Club 2008; 148: 17.

16. European Association for the Study of the Liver. EASL Clinical Practical Guidelines: Management of alcoholic liver disease. J Hepatol 2012; 57: 399-420.

17. Becker U, Deis A, Sørensen TI, Grønbaek M, Borch-Johnsen $\mathrm{K}$, Müller CF, et al. Prediction of risk of liver disease by alcohol intake, sex, and age: a prospective population study. Hepatology 1996; 23: 1025-29.

18. Tam TW, Midanik LT. The effect of screening on prevalence estimates of alcohol dependence and social consequences. $J$ Stud Alcohol 2000; 61: 617-21.

19. Bernadt MW, Mumford J, Taylor C, Smith B, Murray RM. Comparison of questionnaire and laboratory tests in the detection of excessive drinking and alcoholism. Lancet. 1982; 1: 325-8.

20. Sato N, Lindros KO, Baraona E, Ikejima K, Mezey E, Järveläinen HA, et al. Sex difference in alcohol-related organ injury. Alcohol Clin Exp Res 2001; 25(5 Suppl ISBRA): 40S$45 \mathrm{~S}$.

21. Wechsler H, Austin SB. Binge drinking: the five/four measure. J Stud Alcohol 1998; 59: 1224.

22. Barrio E, Tomé S, Rodríguez I, Gude F, Sánchez-Leira J, Pérez-Becerra E et al. Liver disease in heavy drinkers with and without alcohol withdrawal syndrome. Alcohol Clin Exp Res 2004; 28: 131-6.

23. Vuittonet CL, Halse M, Leggio L, Fricchione SB, Brickley M, Haass-Koffler CL, Tavares $\mathrm{T}$ et al. Pharmacotherapy for alcoholic patients with alcoholic liver disease. Am J Health Syst Pharm 2014; 71: 1265-76.

24. Kotb MA. Molecular mechanisms of ursodeoxycholic acid toxicity \& side effects: ursodeoxycholic acid freezes regeneration \& induces hibernation mode. Int J Mol Sci 2012; 3: 8882-914.

25. Thursz M, Forrest E, Roderick P, Day C, Austin A, O'Grady J et al. The clinical effectiveness and cost-effectiveness of Steroids or Pentoxifylline for Alcoholic Hepatitis (STOPAH): a 2x2 factorial randomised controlled trial. Health Technol Assess 2015; 19: 1-104. 